\title{
Anatomic Response
}

National Cancer Institute

\section{Source}

National Cancer Institute. Anatomic Response. NCI Thesaurus. Code C156564.

An assessment of the anatomic response (based on changes in size of anatomic

structures) of the disease to the therapy. 